\title{
Application of Molecular Diagnostic Techniques for the Detection of $E$. coli O157:H7: A Review
}

Nateneal Tamerat, Yimer Muktar* and Daniel Shiferaw

College of Veterinary Medicine, Haramaya University, PO Box 138 Dire Dawa, Ethiopia

\begin{abstract}
Shiga-toxin producing Escherichia coli are considering as important emerging food-born bacterial pathogens. Among these kinds of Escherichia coli, serotype $\mathrm{O} 157: \mathrm{H} 7$ is the cause of sporadic and epidemic human cases of hemorrhagic colitis, which can lead to severe life threatening hemolytic uremic syndrome. Majority of cases are associated with ingestion of food or water contaminated with Escherichia coli 0157:H7. This serotype is identified in 1982, and afterward the different pathogenic genes responsible for its virulence are sequenced. As the organism has been involved in many outbreaks of disease in human and animals, it is essential to develop a rapid, reliable and reproducible method of detection. In this review, different deoxyribonucleic acid based genotyping and detection methods are discussed. Genomic techniques like those that pulse field gel electrophoresis and restricted fragment length polymorphism are reviewed and Polymerase Chain Reaction variants are addressed along with some emerging technology like biosensor and microarray. The advantage and disadvantages of each described method are discussed throughout the review. Since each technique has its own merit and demerit, the decision for selection of $E$. coli $\mathrm{O} 157: \mathrm{H} 7$ detection technique will depend mainly on the balance between several factors such as the high speed, sensitivity, specificity, discrimination power, and availability of proper equipment's and skilled man power. Thus, further research is recommended to improve molecular based detection techniques of $E$. coli $\mathrm{O} 157: \mathrm{H} 7 \mathrm{in}$ order to make the detection of this pathogen effective and specific in various regional and reference laboratory.
\end{abstract}

Keywords: Shiga toxin; Genomics; Polymerase chain reaction

\section{Introduction}

The current fast development of global market for food industries is followed by, the emerging of several food born pathogen which revealed a serious health hazard for both developed and developing countries. Therefore, quality and risk assessment of food is the most important tasks for microbial diagnostic laboratories worldwide. The use of molecular biology based technologies for microbial detection play a major role in efficient identification and quantification of pathogenic bacteria like E. coli O157:H7 [1]. Escherichia coli is gram negative, catalase positive, oxidase negative and facultative anaerobic bacillus [2]. It is normal inhabitants of the gastrointestinal tract of human and animals. Only some strains have become highly adapted to cause diarrhea and a range of extra-intestinal diseases. E. coli is routinely characterized by serological identification of somatic $\mathrm{O}$, flagellar $\mathrm{H}$ and capsular $\mathrm{K}$ antigens. However, some serotypes correlate closely with certain diseases so differentiation of pathogenic strains from the normal flora depends on the identification of virulence characteristics [3].

E. coli strains that cause diarrheal diseases are called diarrheaginic E. coli; there are several pathotypes of diarrheaginic E. coli. Among them Entrohemorrhagic E. coli (EHEC) are different since they possess a potent toxin called the Shiga toxin. Due to this toxin, they sometime designated as shiga toxin producing E. coli (STEC). It has been demonstrated that the Shiga toxins released by E. coli O157: H7 and other Shiga toxin-producing E. coli including O26:H11, O111: $\mathrm{H} 8$ and O118:H16, which are named as non-O157 STEC. However, only O157:H7 genotypes cause disease in human but commonly reside in cattle without causing diseases [4]. E. coli, O157:H7 has increased importance worldwide as a public health problem in the past two decades. It is the predominant and most virulent serotype in a pathogenic subset of Vero toxin producing E. coli [5], it is well known to cause diarrhea; hemorrhagic colitis and hemolytic uremic syndrome, a serious long-term complication that primarily affects children and can cause kidney failure and death. In adults can present with thrombotic thrombocytopenic purpura, a severe and often fatal condition similar to hemolytic uremic syndrome, which have no effective treatment [4].

Since E. coli O157:H7 is the normal flora of the ruminant, mainly cattle serve as reservoir of the organism. As a result, the presence of VTEC in animal feces provides the potential for these organisms to enter in the food chain by fecal contamination of milk products, contamination of meat with intestinal contents during the slaughter process or contamination of fruit and vegetables by contact with infected manure. VTEC are also transmitted through contaminated water and by direct contact with infected people or animals. Following such ways for contamination of food, many out breaks are reported all over the world in which intensive tracing and detection are needed to identify the pathogen. This is done rapidly and accurately by application of molecular technique [6]. In particular, food industry is very demanding in methods of detection to guarantee the safety of their products.

To identify and differentiate the multiple types of diarrheagenic E. coli in the laboratory, a wide variety of methods are employed. Some of them include culturing on specific growth media, assessing biochemical profiles, serotyping and screening for the presence of virulence characteristics. However, these conventional methods are not rapid and reliable enough to distinguish such pathogenic strains

*Corresponding author: Yimer Muktar, College of Veterinary Medicine, Haramaya University, PO Box 138 Dire Dawa, Ethiopia, Tel: +82325607169; Fax: +251925920594; E-mail: yimermktr21@gmail.com

Received March 25, 2016; Accepted July 18, 2016; Published July 22, 2016

Citation: Tamerat N, Muktar Y, Shiferaw D (2016) Application of Molecular Diagnostic Techniques for the Detection of E. coli O157:H7: A Review. J Vet Sci Technol 7: 362. doi:10.4172/2157-7579.1000362

Copyright: (c) 2016 Tamerat N, et al. This is an open-access article distributed under the terms of the Creative Commons Attribution License, which permits unrestricted use, distribution, and reproduction in any medium, provided the original author and source are credited. 
which lead to the application of the molecular diagnostic technique for more effective detection and characterization of E. coli O157:H7 [4]. Therefore, this paper is aimed to discuss the major molecular diagnostic techniques for detection and genotyping of E. coli $\mathrm{O} 157: \mathrm{H} 7$ and highlight the merit and demerit of each method.

\section{History and Evolutionary Origin of E. coli O157:H7}

In 1885, the German pediatrician Theodore Escherich first described the rod shaped organism that bears his name and he called it Bacterium coli, this name was later changed to Escherichia coli to honor his work [4]. Since 1977, it has been recognized that some diarrhoegenic strains of $E$. coli produce toxins that have an irreversible cytopathic effect on cultured Vero cells [3] they are also described as Shiga toxin-producing E. coli due to the similarity demonstrated with Shiga toxins of Shigella dysenteriae [7]. But it is in 1982, VTEC serotype O157:H7 was implicated in outbreaks of Haemorrhagic Colitis (HC) and Hemolytic Uraemic Syndrome (HUS) for the first time, since then it has an increasing world-wide importance as a public health threat [8].

From evolution point of view there is evidence that $\mathrm{O} 157: \mathrm{H} 7$ strains have diverged into two distinct lineages, lineages I and II [9]. Analysis of O157:H7 strains showed that lineage I strains are more commonly associated with human disease than lineage II strains. This suggests that there may be differences in virulence characteristics or transmissibility between these two taxonomic groups of O157:H7 strains [10]

In some other study, it has been suggested that $\mathrm{O} 157: \mathrm{H} 7$ arose from another pathotype of $E$. coli called enteropathogenic $E$. coli serotype $\mathrm{O} 55: \mathrm{H} 7$ through sequential acquisition of virulence traits and serotype change [11]. The proposed evolutionary pathway includes lysogenization bystx 2 -converting phage. Followed by a shift in serotype from $\mathrm{O} 55$ to $\mathrm{O} 157$ brought about by acquisition of the $\mathrm{O} 157$ gnd-rfb locus [12]. The organism then acquired the EHEC large plasmid and the ability to ferment sorbitol was lost. The sorbitol-non-fermenting O157:H7 ancestor was subsequently lysogenized with stx1-converting phage. Finally acquiring of a frameshift mutation in the uidA gene resultsthe loss of $\beta$-glucuronidase activity and the evolution of $E$. coli $\mathrm{O} 157: \mathrm{H} 7$ is reached today [13]. Apart the horizontal gene transfer by conjugation, prophases have a role in the evolution processes which are also associated with divergence of O157:H7 strains [14].

\section{E. coli O157:H7 Genomics}

A fully extended E. coli chromosome is roughly 1000 times longer than the cell itself. E. coli chromosomes range from 4.500 to 5.520 million base pairs and the E. coli $\mathrm{O} 157: \mathrm{H} 7$ strains are more close to the upper extreme, for instance O157:H7 of Sakai strain has a 5,498,450-bp chromosome [15]. There are over 60 complete genomic sequences of Escherichia species. The total number of different genes among all of the sequenced E. coli strains (the pan-genome) exceeds 16,000 . This very large component of genes has been interpreted to mean that twothirds of the E. coli pan-genome originated in other species and arrived through the process of horizontal gene transfer [16].

An Enterohemorrhagic pathogen E. coli has a circular chromosome and large plasmid, in which there are more divergent content in plasmid than chromosome. E. coli O157: $\mathrm{H} 7$ have virulence factors, which are encoded by the plasmids and pathogenicity Island of the chromosome [17]. The virulence factors along the corresponding genes that encode them are as follows. Type III secretion system: encoded by the Locus of Entrocyte Effacement (LEE). It secret proteins, which cause alterations in host, signal transduction. Intimin: encoded by the eaeA locus used for adherence with intestinal cell [18]. Shiga like toxin 1: encoded with stx 1 and used for prevent the binding of tRNA resulting in the inhibition of protein synthesis. Shiga like toxin 2: encoded by stx 2 and have multiple variant, which is approximately $50 \%$ the same with shiga like toxin 1 at the protein level and have similar pathogenic role. Acid tolerance response system: encoded by gadB and gadC. It is used to survive the harsh acidic milieu of the upper gastrointestinal tract [19]. Hemolysin: encoded by the hlyA gene used for has a wide spectrum of cytocidal activity, attacking, endothelial cells, and renal epithelial cells [18]. Extracellular serine protease: encoded by espP used for cleavage of human coagulation factor $\mathrm{V}$ required for prothrombin and clot formation [20].

\section{Molecular Detection and Genotyping of $E$. coli O157: H7}

There are many ways of detection and genotyping of $E$. coli O157:H7. Among them, the diagram below demonstrates the main methods discussed in this review (Figure 1).

\section{Genomics technique for genotyping of $E$. coli $\mathrm{O} 157: \mathrm{H7}$}

Restriction Endonuclease Analysis (REA): Restriction endonuclease, since their discovery in the 1970s by Daniel Nathans and Kathleen Danna, which is cleavage of simian virus DNA by restriction enzymes, yielded specific fragments, which can be separated using polyacrylamide gel electrophoresis [21,22]. It shows that restriction enzymes can be used for mapping of the DNA for the first time [23]. Now days there are more than 3000 different restriction enzymes identified in different bacteria, which have multiple uses like genotyping, RFLP, PFGE and Southern hybridization analysis [24].

Restriction enzymes recognize a specific sequence of nucleotides [25] and produce a double-stranded cut in the DNA. The recognition sequences usually vary between 4 and 8 nucleotides, and many of them are inverted repeat palindrome, a sequence that reads the same forward and backwards in complementary DNA strands [26] (Table 1).

In the REA of the whole genome, the restriction enzyme can be used to genotype a DNA sample. The sample is first digested with the restriction enzyme to generate many small DNA fragments, and then the different sized fragments separated by polyacrylamide gel electrophoresis. The pattern of bands after electrophoresis reveals the sample subject's genotype [18,27] (Figure 2).

\section{Pulse Field Gel Electrophoresis (PFGE)}

It is whole genome technique done by using restriction enzymes, which cleave the bacterial genome infrequently, to generate small numbers of large DNA fragments to form macro restriction profiles characteristic for one or more isolates. It enables separation of large fragments over $10 \mathrm{Mb}$ unlike REA, which separate only small fragment $30-50 \mathrm{~kb}[29]$.

The detection of O157:H7 with the help of PFGE include, first bacteria were embedded in agarose, lysed, treated with protease and intact genomic DNA is released. Secondly, DNA was digested with restriction end nuclease. Then fragments of DNA were separated in agarose gels on a clamped homogenous electric field apparatus and Gels were stained with ethidium bromide. Finally, destained in water, and visualized with a Gel Doc gel analysis system [30]. Patterns can be submitted to PulseNet central for comparison to the E. coli O157:H7 PFGE pattern database [31].

PFGE requires highly technically skilled personnel but it is considered as the gold standard method for typing of E. coli $\mathrm{O} 157$ due to its high level of discrimination and accuracy and reproducibility. It also 


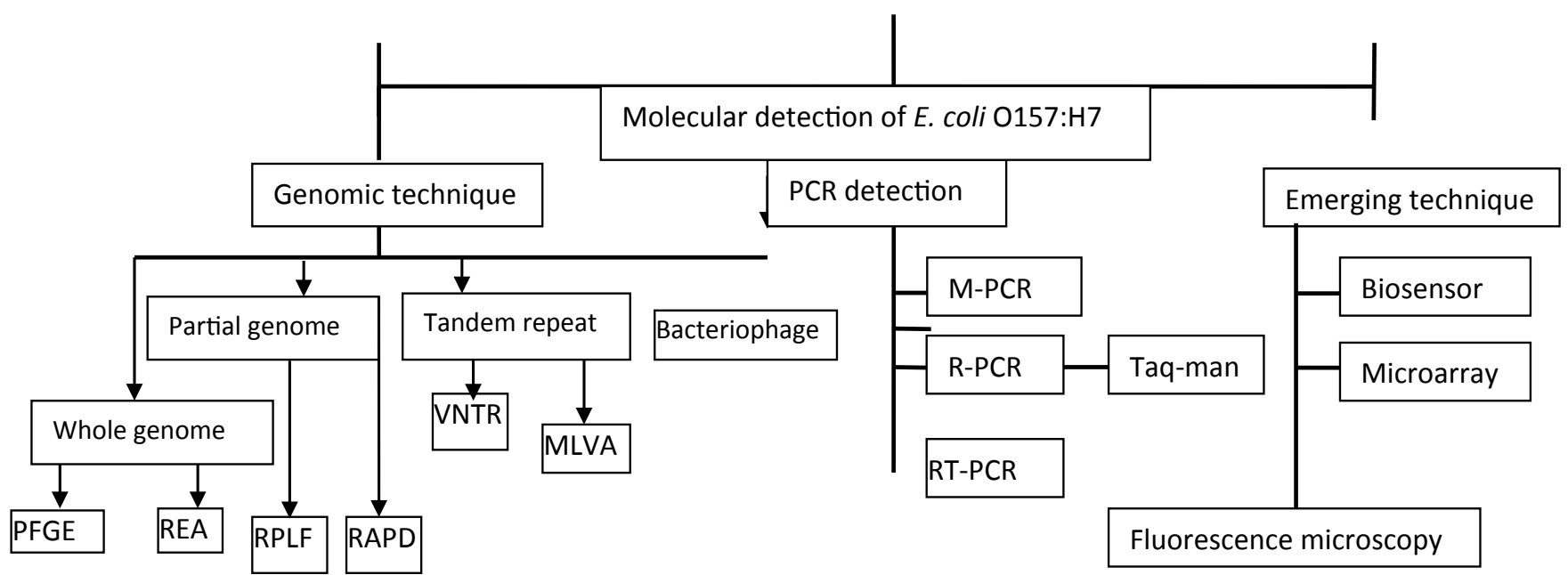

Source: Nateneal et al. [21].

Figure 1: Molecular technique for detection and genotyping of E. coli O157:H7.

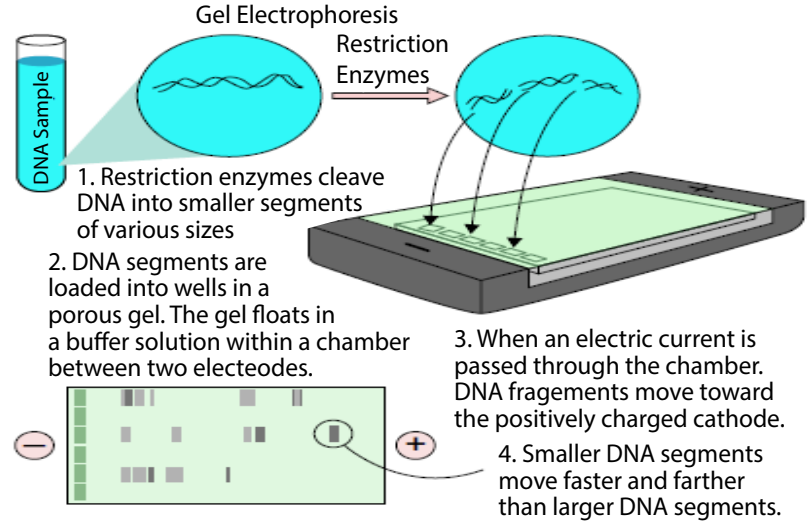

Figure 2: DNA digestion and gel electrophoresis. Source: Betsy [28].

\begin{tabular}{|c|c|c|c|}
\hline Enzyme & Source & $\begin{array}{c}\text { Recognition } \\
\text { Sequence }\end{array}$ & Cut \\
\hline EcoRI & Escherichia coli & 5'GAATTC & 5'---GAATTC---3 \\
\hline Taql & Thermus aquaticus & 3'CTTAAG & 3'---CTTAAG---5' \\
\hline & & 3'AGCT & 5'---TCGA---3' \\
\hline
\end{tabular}

Source: Robert [27].

Table 1: Example of two restriction enzymes with their restriction sequence.

has the advantage of generating genetic data which can be statistically analysed. In PulseNet, a network of public health laboratories performing a standardized PFGE method that allows comparison of fingerprints held on an electronic database by the Centres for Disease Control and Prevention OIE [5] (Figure 3).

\section{Restriction Fragment Length Polymorphism (RFLP)}

It is partial genomic technique, which includes restriction digestion of genomic DNA and hybridization with a probe designed to detect regions of DNA complementary to the probe after electrophoresis of the fragment. Several genomic targets DNA have been exploited as epidemiological markers including ribosomal RNA genes and VTencoding genes of the bacterial chromosome [29].

The procedure of RFLP to genotype E. coli O157:H7 is as follows; first DNA of the sample is purified and digested with restriction enzyme. Then restricted DNA fragments were separated after electrophoresis in agarose [20]. Following electrophoresis Southern blots were performed, means DNA was transferred to Nytran membranes and hybridized with 32P dCTP-labelled stx 1 and stx2 probes [33] and visualization is done by exposure to X-ray film but due to safety issue now a day's non-radio-active methods replace the use of $32 \mathrm{P}$ by chemiluminescent system [34].

It has considerable simplification over REA because the probes are complementary only to target sequence so that hybridization take place unlike REA which use pattern of band made by the whole DNA fragments [34]. The specific bands detected Polymorphism, and the band size is used to subtype strains so analysis involves comparison of multiple bands based on size. Even if RFLP-based methods are commonly used in routine typing, unlike PFGE the ability to standardize and digitalize data generated for inter laboratory comparisons has its own limitations [29,35-38].

\section{Random Amplified Polymorphic DNA (RAPD)}

It is DNA based methods, in which detection is by using short random oligonucleotides about 10 bases of various sequences as primers to amplify the intervening sequences in a PCR reaction. Number and location of the primer binding sites and intervening sequences vary according to the strain identified [39].

In RAPD after DNA extraction, oligonucleotides having any base sequence which is used in these technique as an oligonucleotide synthesizer can prepare a primer and each primer can generate a specific DNA profile per sample. After the completion of amplification by PCR, the amplified products were separated by electrophoresis on agarose gel then ethidium bromide is added and the gel was finally visualized by UVtransilluminator. Interpretation of results: is based on the polymorphism of the amplified bands run on agarose gel [40] (Figure 4).

It is important that RAPDs approach does not utilize restriction enzymes and probes of any kind. Rather it utilizes a DNA polymerase 

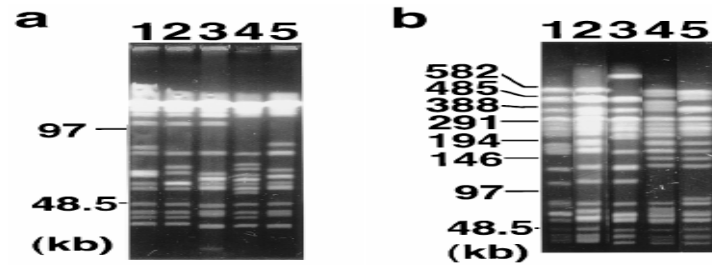

Figure 3: a) An example PFGE pattern of O157:H7 strains isolated in five district of Japan represented by the five lanes. b) Separation of the whole genome of O157:H7. Source: Hidemesa et al. [32].

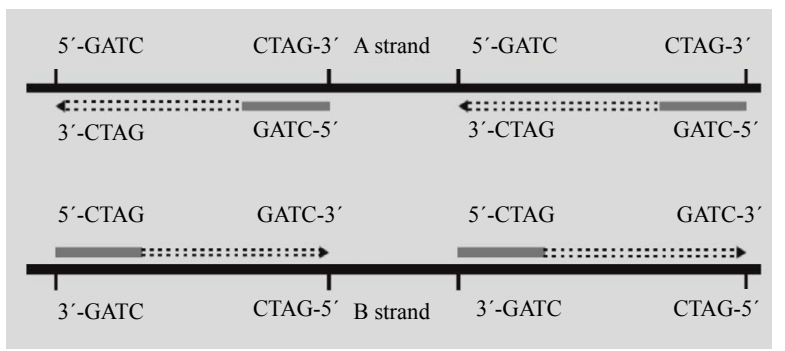

Source: Robert et al. [20]

Figure 4: An example of Random amplification of sequences with random primer.

in PCR which is resistant to the high temperatures needed for DNA denaturation, so that it is reused repeatedly during DNA amplification. So this make the RAPDs to save some cost due to this their use is expanding [41].

Most importantly, RAPD has the advantage of requiring no prior knowledge of DNA sequences of the target and the Entire genome of the organism can serve as a target. Even though RAPD have more discriminatory power than RFLP it has the disadvantage of Low reproducibility and risk of contaminated DNA amplification [42].

\section{Variable Number Tandem Repeat (VNTR)}

In Variable Number Tandem Repeat, thousands of copies in some prokaryote genomes disperse randomly repeated sequences. Loci with short sequence repeats of $1-13 \mathrm{bp}$ are generally referred to as microsatellites and those with $10-100$ bp sequence repeats as mini satellites. VNTR is a tool for genotyping and it provides data in a simple and nonambiguous format based on the number of repetitive sequences [35]. However, many aspects of the mechanisms of the variability, its biological roles and its involvement in evolutionary processes remain mysterious. These loci have a characteristic structure consisting of a variable number of near-identical repeated DNA sequences arranged consecutively [36].

In VNTR technique, DNA containing variable number of tandem repeat sequence amplified by PCR and the size of the product is determined by electrophoresis on agarose gel followed by ethidium bromide. So based on the size of PCR product, the exact number of tandem repeats at each locus in each pathogenic strain was determined including O157:H7 [37].

\section{Multilocus Variable-Number Tandem Repeat analysis (MVTR)}

Multilocus variable-number tandem repeat analysis (MLVA) is a DNA-based molecular typing method that determines the number of repeats at multiple variable-number tandem repeat loci, i.e., areas that evolve quickly in the bacterial genome [29]. MLVA records size polymorphisms in several variable number of tandem repeats loci amplified by stringent PCR protocols. There are several variations of MLVA assays depending on available instrumentation. Earlier versions tended to measure VNTR sizes by agarose gel electrophoresis, while newer assays often use capillary electrophoresis for size determination once the allele size range at each locus has been well-characterized [38].

MLVA correctly identified the isolates from all outbreaks of $E$. coli O157:H7. It is being a simple and validated method for E. coli O157:H7 outbreak detection, MLVA appears to have sensitivity equal to that of PFGE and specificity superior to that of PFGE [39].

MLVA will mainly impacts the public health field by introducing newer, faster and safer methodologies for typing. It reduces typing time with high resolution, which is beneficial for resolving large and complex outbreak situations. The methodology is also suitable for large-scale automation. The only drawback is its high assay-specificity and as a result, there is lack of standardization for the majority of published assays [38].

\section{Bacteriophage typing}

It is a form of typing in which strains of bacteria are distinguished on the basis of differences in their susceptibilities to a range of bacteriophage [18]. It is the most widely used conventional sub-typing method for E. coli O157:H7 in Europe OIE [5]. Bacteriophage typing of O157:H7 include the following procedure, first flood plate is prepared from a culture of the unknown strain of O157:H7 then allow it to dry by just leaving the plate with the lid partly off and a grid is drawn on the base of the plate [18].

Secondly the squares of the grid is inoculated with one drop of a phage suspension each square being inoculated with a different phage then incubated [18] the susceptibility of each isolate to lysis by a panel of 16 bacteriophages is determined and the lytics patterns obtained usually allow typing in to one of 82 possible types of O157:H7 [29]. So in a given gride if there is phage, which lyses the particular 0157:07 strain and it will form a clear macroscopic area, amid the opaque layer of bacterial growth. So the strain can then be defined in terms of the phages to which it is sensitive [18].

Even if Bacteriophage typing is useful for E. coli O157:H7 subtyping, it is not applicable to non-O157 VTEC and it may be affected if the bacterium under test carries a plasmid encoding a restriction endonuclease which destroys phage nucleic acid. So it does not usually provide the level of discrimination required for epidemiological and outbreak investigations [29].

\section{PCR based method for $E$. coli O157:H7 detection}

Back ground to PCR: Molecular biology has been revolutionized by PCR that efficiently increases the number of DNA molecules in a logarithmic and controlled fashion. The concept of DNA amplification by PCR is simple and its impact has been extraordinary. Kary Mullis invented PCR in 1985, every year thereafter the number of papers on PCR has risen exponentially [43].

DNA extraction from bacteria isolates: The success of any PCR based pathogen screening method is directly dependent on the efficacy of nucleic acid extraction method employed [44]. There are several methods of extraction but among them the boiling method of DNA extraction was most sensitive for E. coli detection [45]. E. coli DNA extraction by boiling method is done by making bacterial suspension and boiling it at $100^{\circ} \mathrm{C}$. Then the supernatant was used as DNA template for PCR after centrifugation [46]. 
Components of PCR: There are several inputs required for PCR amplification, each with their own purpose as follows. Buffer: it provides ionic strength and buffering capacity during the reaction. Especially the cations within it prevent the repulsive force between the negatively charged backbones of dsDNA, which facilitates the annealing process [43].

dNTP: Deoxynucleotide tri phosphates are the raw materials used to build the amplicons along with the primers and template. They are four in number dATP, dTTP, dGTP and dCTP [43]. Primers are 5'3 ' oligonucleotides of about 20 nucleotides in length. They are two primers designed to be complementary to the flanking sequences of the target area on each strand and serve as a base for the extension step DNA template: it is the initial DNA for amplication, which include the target sequence and site for prime binding of $E$. coli. Taq polymerase is temperature resistant enzyme used to form the complementary stand using free dNTP during elongation after the annealing of the primer [47] (Table 2).

\section{PCR phase}

There are three phases of PCR: these are Denaturation, Annealing and Elongation, which are repeated in each cycle of the PCR. Denaturation: when a double stranded DNA molecule is sufficiently heated $\left(94^{\circ} \mathrm{C}\right)$, the hydrogen bonds holding together the double helix are disrupted and the molecule separates or denatures into single strands. This allows the primers access to the single stranded DNA templates, Annealing: the reaction mixture is cooled (about $50^{\circ} \mathrm{C}$ ) to allow primers to select and bind (hybridize) to their complementary positions on the ssDNA template molecules, which is the exact sequence of nucleotides that flank the area of interest, and Elongation: when the ssDNA/primer solution is heated to $72^{\circ} \mathrm{C}$, the heat stable polymerase reads a template DNA in the $3^{\prime}-5^{\prime}$ direction and synthesis a new complementary template in the 5'-3' direction, using free dNTP's as building blocks in the presence of PCR buffer [43]. With each repetition of this cycle, the target is doubled and after about 30 cycles, the reaction will yield in excess of 1 million copies of the target DNA fragment, which make it easily detected by conventional methods such as gel electrophoresis due to the DNA $[43,48]$.

\section{Variant of PCR for detection of $E$. coli O157:H7}

Several variation of the standard PCR have recently appeared and these have assisted in producing more sensitive detection methods. Among them, multiplex PCR and real-time PCR are proving to be the most popular. The former allows several targets to be co-amplified in one PCR [49]. Real-time PCR allows reactions to be characterized by the time when amplification of the PCR product is first detected by use of a fluorogenic probe [50].

\section{Multiplex PCR (m-PCR)}

One limitation of a single gene PCR assays is that there are no single markers that provide definitive identification for $\mathrm{O} 157: \mathrm{H} 7$. This is primarily because $E$. coli $\mathrm{O} 157: \mathrm{H} 7$ is genetically similar to most other E. coli strains that are commonly found in gastrointestinal tract of human and animals and most of the virulence associated genes targeted for PCR amplification are widespread in non-O157 E. coli isolates [20]. But this problem is solved by Multiplex PCR assay which allows several targets to be co-amplified simultaneously in the same reaction by combining several primer pairs [8]. So the identification of the major virulence genes of $E$. coli without the need for restriction enzyme digestion and the differentiation of O157:H7 isolates from non-O157:H7 isolates is possible by application of multiplex PCR [20].
In recent years, PCR has been used increasingly for rapid, sensitive, and serotype-specific detection of low levels of O157:H7 in feces, foods, water, and environmental samples. Several serotype specific genes such as $\mathrm{rfb}$, uidA and fliC. Also virulence associated gens like eaeA, hlyA, stx1 and stx 2 have been used for genotyping and detection of $\mathrm{O} 157: \mathrm{H} 7$ in m-PCR formats [4] (Table 3).

The routine multiplex PCR procedure is as follows, first extract the DNA by boiling method. Secondly, prepare the master mix, which contain all the input of PCR apart the template. After preparation, dispense the mix into PCR reaction tube followed by addition of boiled culture (crude DNA extract). Then run the PCR using cycling parameters of the standard time and temperature. After this, the post PCR analysis began by running the PCR product on agarose gel and Stained by ethidium bromide followed by trans illumination. Finally, to identify positions of stx 1 , stx 2 and eae amplicons compare with the bands of test sample lane [5].

\section{Real-time PCR}

Conventional PCR relies on amplification of the target genein a thermo cycler, separation of PCR products by gel, followed by visualization and analysis of the resultant electrophoresis patterns, which is a process that can take a number of hours. But the development of real-time PCR, which uses fluorescence to detect the presence of a particular gene in real time, has greatly increased the sensitivity and speed of PCR-based detection methods without the need electrophoresis [29].

Most of the R-PCR assays that have been developed for the identification of O157:H7 are based on the detection of stx encoding Stx-toxins, eae-intimin and O-antigen [29]. These R-PCR assays offer the opportunity to quantify the absolute and relative amounts of O157:H7 in complex sample matrices. There are different modes of R-PCR among them the most commonly used R-PCR systems are the TaqMan PCR [20].

\section{TaqMan PCR}

A fluorogenic oligonucleotide probe complementary to the target gene is labeled with a fluorescent reporter dye at 5'end and a fluorescent quencher dye at the 3 'end in detection system. This probe binds to its complementary sequence within the target gene selected for amplification by flanking primers. During amplification, $5^{\prime} \rightarrow 3^{\prime}$ nuclease

\begin{tabular}{|c|c|c|}
\hline Designation - Sequence- (5 3') & Target gene & $\begin{array}{c}\text { Amplicon size } \\
\text { bp }\end{array}$ \\
\hline $\begin{array}{c}\text { SK1 CCC GAA TTC GGC ACA AGC ATA AGC } \\
\text { SK2CCC GGA TCC GTC TCG CCA GTA TTC G }\end{array}$ & eae & 881 \\
\hline Stx com-u GAG CGA AAT AAT TTA TAT GTG & & \\
\hline Stx com-d TGA TGAs TGG CAA TTC AGT AT & stx & 518 \\
\hline
\end{tabular}

Source: Toma et al. [48]

Table 2: Primers used for EHEC detection with target gene of eae and stx.

\begin{tabular}{|c|c|c|c|}
\hline $\begin{array}{c}\text { Target } \\
\text { gene }\end{array}$ & Primer sequence & $\begin{array}{c}\text { Nucleotide } \\
\text { position }\end{array}$ & $\begin{array}{c}\text { Amplicon } \\
\text { size }\end{array}$ \\
\hline Stx1 & F (5'-CGC-TCT-GCA-ATA-GGT-ACT-CC-3') & $287-306$ & 256 \\
\hline & R(5'-CGC-TGT-TGT-ACC-TGG-AAA-GG-3') & $522-541$ & \\
\hline Stx2 & F(5'-TCC-ATG-ACA-ACG-GAC-AGC-AG-3') & $623-642$ & 185 \\
\hline & R (5'-GC-TTC-TGC-TGT-GAC-AGT-GAC-3') & $788-807$ & \\
\hline eaeA & F(5'-GC-TTA-GTG-CTG-GTT-TAG-GAT-TG-3 & $271-293$ & 618 \\
\hline & R (5'-CCA-GTG-AAC-TAC-CGT-CAA-AG-3') & $871-890$ & \\
\hline
\end{tabular}

Source: OIE [5].

Table 3: Example targets stx, stx and eae genes for Multiplex PCR. 
activity of the Taq DNA polymerase cleaves the probe, separating the quenching dye from the reporter dye leading to the increased fluorescence emission [2]. Fluorescent intensity is then measured by a fluorometer and the emission data is analyzed for the detection of a "positive" or "negative" result for the target genes. Fluorescence intensity is proportional to copy number there by allowing quantitative analyses and eliminates the need for post-PCR analysis unlike the conventional PCR. Moreover, because of the automation, these assays can be easily adapted for high-throughput applications [45] (Figure 5).

Most of these assays target single genes therefore lack diagnostic specificity by themselves, which could lead to problems of cross reactivity (false positives) with other closely related organisms. For instance, R-PCR assays that target stx genes may cross react with other non-O157 STEC and fail to discriminate between O157:H7 and other E. coli [45]. Some published reports have shown that the specificity and sensitivity of R-PCR assays can be improved by using a combination of two or more primer sets (multiplex-R-PCR assay) in one reaction [52] although in practice is it not possible to multiplex more than four markers due to the limits of overlapping excitation of emission spectra of available fluorphores [20].

\section{Reverse transcriptase PCR (RT -PCR)}

Conventional PCR and R-PCR assays rely upon a DNA template for amplification. But this DNA can, persist in the sample even after cell death thereby leading to positive detection of nonviable cells [53]. This could be a significant disadvantage and could be construed as false detection events because nonviable bacteria present no health risks. Such kind of shortcoming is addressed by RT-based assay which is developed for the detection of viable O157:H7 in foods and environmental samples [45].

The RT-PCR relies on synthesizing single-stranded complementary DNA from mRNA by RT in the 5-3 direction for subsequent PCR amplification [49] and it can only detect viable cells because mRNA is present only in actively growing cells and unlike DNA, mRNA tends to degrade rapidly (half-life of mRNA is only up to $20 \mathrm{~min}$ ) in dead cells, thus allowing detection of only viable cells in a sample [54].
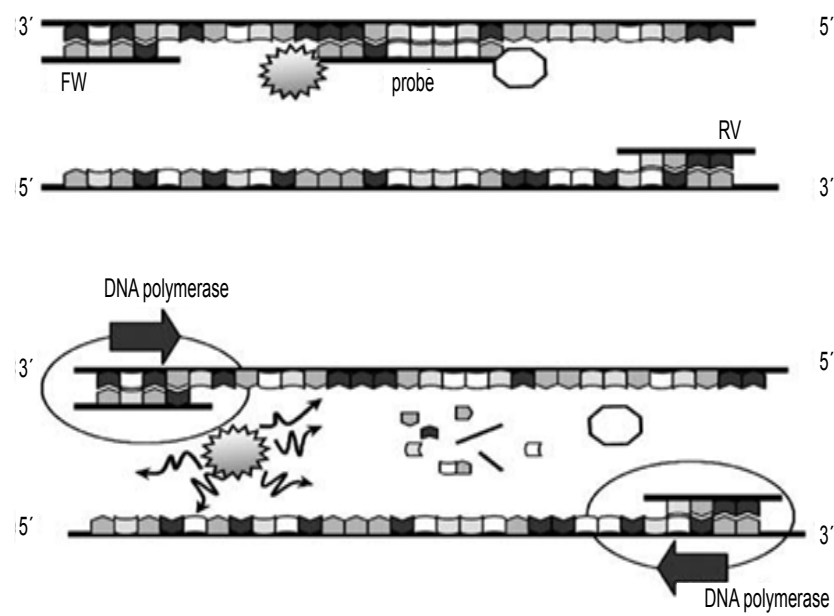

Source: George and Wilhelm [51]

Figure 5: Shows the dual-labeled TaqMan probe is cleaved by the 5-exonuclease activity of Taq DNA polymerase during the extension step of the PCR reaction. The quencher and fluorophore are brought apart, which results in an increase in fluorescent emission.
Studies shows that $\mathrm{rfbE}$ and stxl mRNAs were more suitable targets for detecting both viable as well as nonculturable cells because these mRNAs were more stable in the viable cells, while having a very short half-life in the heat killed cells [55]. Also the ability of RT-PCR to detect stx2 mRNA from viable O157:H7 cells was influenced by growth conditions with the best detection of stx 2 mRNA found with late log and early stationary phase cells [53].

The target mRNA is constitutively expressed in viable cells, including healthy, dormant, injured or nonculturable cells. Furthermore, the expression of bacterial virulence factors is often influenced by various environmental and stress conditions that organisms may encounter in different food matrices and environments. For instance, Stx production has been shown to be reduced with reduced aeration and reduced growth temperature $\left(32^{\circ} \mathrm{C}\right)$. Therefore, to use RT-PCR as a means of specifically identifying bacteria, care must be taken to ensure abundant and dependable expression of target mRNA [45].

\section{Disadvantages of PCR}

PCR can amplify dead cells and care must be taken in designing the experiments. Furthermore, this makes data interpretation complex. The pre enrichment step, which is used to increase the sensitivity of PCR, is laborious and time-consuming process [8].

The application of PCR assays for the specific detection of O157:H7 directly from sample matrices such as feces or different types of foods is often challenging because these samples not only contain very low numbers of O157:H7 organisms but also a high amount of background flora. Additionally, the samples may carry PCR inhibitory substances such as heme in blood and meat samples, heavy metals, complex humic acids and fulvic substances in feces and soils, and polyphenolic compounds in acidic foods such as apple cider. Inhibitors can also squelch fluorescent signal from fluorophores used in R-PCR [45].

The processes of DNA extraction before PCR analysis is time consuming. In addition, it is expensive using costly reagents and chemicals, labor intensive with a need of skilled technician and there is a risk of contamination, which in turn decreases its efficiency. Moreover, PCR requires very small application volumes of DNA that is extracted from high sample volumes in the presence of matrix associated compounds that may interfere with enzymatic nucleic acid amplification. This and other problems of PCR leads to the need for the development of new emerging technology which are intended to address some of its drawbacks [43].

\section{Emerging Technology}

These are DNA based technology, which improves the existing methods by adding some features like automation and specification to increase the performance of the identification techniques. Here are some of the upcoming techniques used for detection of food born pathogen including O157:H7 [2].

\section{The Biosensors}

Current methods to detect and confirm the presence of STEC in a sample are time consuming, especially if they require enrichment protocols. They also might be too complex and costly for use in routine analysis. Rapid detection and confirmation PCR assays have recently been developed but inhibition of PCR by compounds present in matrices such as food or feces can lead to difficulties and false-negative results [20].

As a result, new approaches based on the use of biosensors have been described. Biosensors combine a biological recognition element 
in contact with a physicochemical detection component. They convert an optical, piezoelectric or electrochemical signal modified by a biological response into an electrical signal. They aim for a rapid and reliable detection of pathogens in complex matrix without the use of enrichment or any other additional steps (e.g., washing). There are different variant of biosensor like fiber optic based biosensor, resonant acoustic profiling and Surface Plasmon resonance which can be used for detection of the E. coli O157:H7 [2].

\section{The Fluorescence and Microscopy}

The detection of fluorescent E. coli O157:H7 by confocal scanning laser microscopy has been tested in a study [56]. E. coli O157:H7 cells labelled with an enhanced green fluorescent protein plasmid were submitted to treatments with chlorine, hydrogen peroxide and acetic acid. Change in fluorescence intensity was measured with a spectrophotometer and individual cells were observed with a confocal scanning laser microscope [2]. Other studies have investigated a flow cytometric (FCM) approach for the detection of E. coli and authors highlighted the fact that FCM allow the detection of 104 bacterial cells in a few minutes, which is faster than any other methods to detect pathogenic cells with viability in food samples [57].

Laser-induced fluorescence coupled with flow cytometry was used to detect $E$. coli $\mathrm{O} 157: \mathrm{H} 7$ in ground beef. The authors reported that this approach offers several advantages over currently available techniques including automated examining large quantities of food in real time; detect single organisms whereas other methods may require more than 104 microbe [58]. Also it is specific for the organisms being studied. It is believed that this system can provide the sensitivity and specificity required for the detection of pathogenic bacteria [8].

\section{The Microarray}

Microarray is a device that allows thousands of specific DNA or RNA sequences to be detected simultaneously on a small slide; this has allowed more rapid analyses to take place [8]. Nucleic acid microarrays employed for detection and genotyping of bacterial pathogens [59]. Microarrays are well known for their application in the whole genome expression profiling of bacterial pathogens [60].

From food safety perspective, microarrays can also be used for bacterial gene identification as well as pathogen surveillance. For these applications, labeled nucleic acid targets (PCR products, genomic DNA, rRNA, etc.) are hybridized to a microarray chip where upon target probe duplexes are typically detected using some type of direct or indirect fluorescent signal system. The relative signal from each probe is detected and quantified by using a confocal laser or filtered light scanner [61] (Figure 6).

Viable but non culturable (VBNC) E. coli may also represent a threat, especially in drinking water. Microarrays have developed a sensitive method to detect VBNC O157:H7 in water. RNA encoding the $\mathrm{rfbE}$ and fliC-H7 genes was chosen as viability markers and was detected with an electronic microarray. Fifty VBNC O157:H7 were detected in $1 \mathrm{~L}$ of river water [62].

The major advantage of the microarray assay over agarose gel analysis of the PCR products is that microarray does not rely on the length of the PCR products for identification. In addition, when there is a need to couple it with PCR, microarray based analysis can improve analytic sensitivity, diagnostic sensitivity, and diagnostic specificity of $\mathrm{O} 157: \mathrm{H} 7$ and these methods offer attractive advantages over conventional detection systems [45].

There are some disadvantages also like expensive instrument, of limited availability and require specialist knowledge and training to extract useful information from the huge amount of data generated [8]. Some of the technical problems associated with data interpretation of a microarray include high background interference especially at low signal output, and the differences in efficiency of nucleic acid labeling and variations in the experimental conditions in each laboratory can affect the interpretation of results [63]. So more work is needed for inter-laboratory validation of microarray based assays before this technology is likely to impact our ability to routinely test for O157:H7 [8].

\section{Conclusion and Recommendations}

Although conventional microbiological procedures remain an integral part of detection methods they are laborious and time consuming. However, molecular identification of genetic loci encoding virulence associated markers has greatly facilitated development of detection and genotyping of O157:H7. PFGE is considered as gold standard method for typing of O157:H7 due to its high level of

\section{Preparation and fabrication Target screening Data analysis and interpretation}

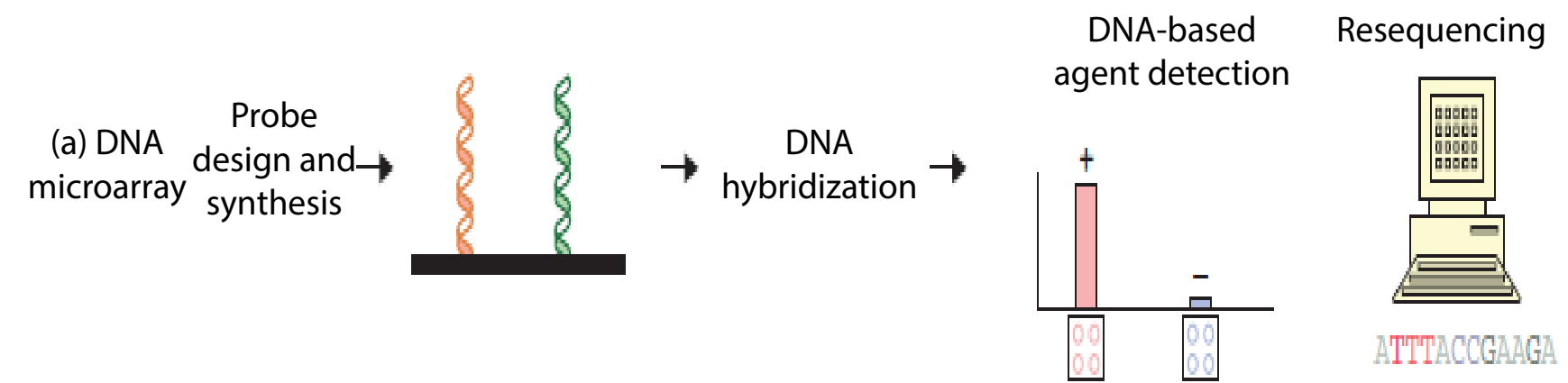

Source: Betsy [28] 
discrimination and reproducibility whereas multiplex PCR and R-PCR, enable the rapid simultaneous detection of several virulence-associated markers and allows the detection of E. coli O157:H7 at real time, respectively. Emerging technologies like biosensor and microarray can provide real-time measurements and rapid analysis without the need of pathogen isolation. Even if isolation of bacteria followed by molecular detection method like m-PCR is considered as the method of choice, each technique have its own merit and demerit, the decision for the selection of detection technique will involve striking a balance between several factors such as the speed, sensitivity, specificity, discrimination power and availability of proper equipment's, skilled personnel and the cost involved in detection procedures. Therefore, based on the above conclusion, further research should be made to develop more specific and efficient molecular technique in order to enhance and promote the capacity of various reference and regional laboratory in molecular techniques for diagnosis of food pathogen including O157:H7.

\section{References}

1. Beneduce L, Fiocco D, Spano G (2007) Development of PCR-based molecula tools for the detection of emerging food- ad water-borne pathogenic bacteria. Communicating Current Research and Educational Topics and Trends in Applied Microbiology 569-576.

2. Magni MV (2010) Detection of Bacteria, Viruses, Parasites and Fungi. NATO Science for Peace and Security Series. Bioterrorism prevention. Springer. Pp. 53-86.

3. Konowalchuk J, Speirs JI, Stavric S (1977) Vero response to a cytotoxin of Escherichia coli. Infect Immun 18: 775-779.

4. Manning SD (2010) Deadly diseases and epidemics. Escherichia coli Infections 2nd edn. An imprint of Infobase Publishing, 132 West 31st Street New York, NY 10001, USA, Pp: 8-43.

5. OIE (2008) Vero cytotoxigenic Escherichia coli.

6. CDC (2011) General Information Escherichia coli.

7. O'Brien AD, LaVeck GD (1983) Purification and characterization of a Shigella dysenteriae 1-like toxin produced by Escherichia coli. Infect Immun 40: 675-683.

8. Deisingh AK, Thompson M (2004) Strategies for the detection of Escherichia coli O157:H7 in foods. J Appl Microbiol 96: 419-429.

9. Kim J, Nietfeldt J, Wise J, Fegan N, Desmarchelier P, et al. (2001) Ancestral divergence, genome diversification, and phylogeographic variation in subpopulations of sorbitol-negative, beta-glucuronidase-negative enterohemorrhagic Escherichia coli 0157. J Bacteriol 183: 6885-6889.

10. Yang Z, Kovar J, Kim J, Nietfeldt J, Smith DR, et al. (2004) Identification of common subpopulations of non-sorbitol-fermenting, beta-glucuronidasenegative Escherichia coli 0157:H7 from bovine production environments and human clinical samples. Appl Environ Microbiol 70: 6846-6854.

11. Wick LM, Qi W, Lacher DW, Whittam TS (2005) Evolution of genomic content in the stepwise emergence of Escherichia coli O157:H7. J Bacteriol 187: 1783-1791.

12. Tarr PI, Schoening LM, Yea YL, Ward TR, Jelacic S, et al. (2000) Acquisition of the rfb-gnd cluster in evolution of Escherichia coli $\mathrm{O} 55$ and O157. J Bacterio 182: 6183-6191.

13. Feng P, Lampel KA, Karch H, Whittam TS (1998) Genotypic and phenotypic changes in the emergence of Escherichia coli O157:H7. J Infect Dis 177 1750-1753.

14. Ohnishi M, Kurokawa K, Hayashi T (2001) Diversification of Escherichia coli genomes: are bacteriophages the major contributors? Trends Microbiol 9 : 481-485

15. Hayashi T, Makino K, Ohnishi M, Kurokawa K, Ishii K, et al. (2001) Complete genome sequence of enterohemorrhagic Escherichia coli 0157:H7 and genomic comparison with a laboratory strain K-12. DNA Res 8: 11-22.

16. Zhang L, Srinivasan U, Marrs CF, Ghosh D, Gilsdorf JR, et al. (2004) Library on a slide for bacterial comparative genomics. BMC Microbiol 4: 12.

17. Nicole T, Jeremy D, Glasner V, Burland G, Plunkett H (2002) The Genomes of Escherichia coli $\mathrm{K}-12$ and Pathogenic E. coli. Genomics, Evolution and Pathogenesis. San Diego: Elsevier Science, pp: 3-44.
18. Singleton P, Sainsbury D (2006) Dictionary of Microbiology and Molecular Biology. 3rd edn. John Wiley \& Sons Ltd, USA.

19. Thorpe CM, Ritchie JM, Acheson DWK (2002) Enterohemorrhagic and other Shiga toxin producing Escherichia coli. Escherichia coli: Virulence mechanisms of a versatile pathogen. pp: 119-154.

20. Levin RE (2010) Rapid Detection and Characterization of Foodborne Pathogens by Molecular Techniques. Taylor \& Francis Group, pp: 33-56

21. Nateneal T (2013) Application of molecular diagnostic techniques for the detection of E. coli O157:H7: a review. Senior Seminar on Animal Health College of Veterinary Medicine, Haramaya University, Ethiopia.

22. (1978) The Nobel Prize in Physiology or Medicine, The Nobel Foundation.

23. Danna K, Nathans D (1971) Specific cleavage of simian virus 40 DNA by restriction endonuclease of Hemophilus influenzae. Proc Natl Acad Sci USA 68: 2913-2917.

24. Kreuzer H, Massey A (2001) Recombinant DNA and Biotechnology. A Guide for Teachers. ASM Press, Washington. D.C, USA, Pp: 648.

25. Kessler C, Manta V (1990) Specificity of restriction endonucleases and DNA modification methyltransferases a review (Edition 3). Gene 92: 1-248.

26. Clark DP, Pazdernik NJ (2005) Molecular biology. Amsterdam. Elsevier Academic Press, USA

27. Roberts RJ (1981) Restriction and modification enzymes and their recognition sequences. Nucleic Acids Res 9: r75-r96.

28. Foxman B (2010) Molecular Tools and infectious Diseases Epidemiology. Academic Press, San Diego, California, USA, Pp: 63-66.

29. O'Sullivan J, Bolton DJ, Duffy G, Baylis C, Tozzoli R, et al. (2007) Pathogenic Escherichia coli Network. Methods for Detection and Molecular Characterization of Pathogenic Escherichia coli. Co-ordination Action Food-CT-2006-036256.

30. Avery SM, Liebana E, Reid CA, Woodward MJ, Buncic S (2002) Combined use of two genetic fingerprinting methods, pulsed-field gel electrophoresis and ribotyping for characterization of Escherichia coli $\mathrm{O} 157$ isolates from food animals, retail meats, and cases of human disease. J Clin Microbiol 40: 2806-2812.

31. Swaminathan B, Barrett TJ, Hunter SB, Tauxe RV (2001) PulseNet: the molecular subtyping network for foodborne bacterial disease surveillance, United States. Emerg Infect Dis 7: 382-389.

32. Izumiya H, Terajima J, Wada A, Inagaki Y, Itoh KI, et al. (1997) Molecular typing of enterohemorrhagic Escherichia coli 0157:H7 isolates in Japan by using pulsed-field gel electrophoresis. J Clin Microbiol 35: 1675-1680.

33. Kudva IT, Hatfield PG, Hovde CJ (1997) Characterization of Escherichia coll O157:H7 and other Shiga toxin-producing E. coli serotypes isolated from sheep. J Clin Microbiol 35: 892-899.

34. Durr PA, Clifton-Hadley RS, Hewinson RG (2000) Molecular epidemiology of bovine tuberculosis. II. Applications of genotyping. Rev Sci Tech 19: 689-701.

35. Ramazanzadeh R, McNerney R (2007) Variable Number of Tandem Repeats (VNTR) and its application in bacterial epidemiology. Pak J Biol Sci 10: 2612-2621.

36. Mazars E, Lesjean S, Banuls AL, Gilbert M, Vincent V, et al. (2001) Highresolution minisatellite-based typing as a portable approach to global analysis of Mycobacterium tuberculosis molecular epidemiology. Proc Natl Acad Sci U S A 98: 1901-1916.

37. Adair DM, Worsham PL, Hill KK, Klevytska AM, Jackson PJ, et al. (2000) Diversity in a variable-number tandem repeat from Yersinia pestis. $\mathrm{J}$ Clin Microbiol 38: 1516-1519.

38. Lindstedt BA, Torpdahl M, Vergnaud G, Le Hello S, Weill FX, et al. (2012) Use of multilocus variable-number tandem repeat analysis (MLVA) in eight European countries, 2012. Euro Surveill 18: 20385.

39. Vogel L, van Oorschot E, Maas HM, Minderhoud B, Dijkshoorn L (2000) Epidemiologic typing of Escherichia coli using RAPD analysis, ribotyping and serotyping. Clin Microbiol Infect 6: 82-87.

40. Kilic A, Muz A, Ertas HB, Ozbey G (2009) Random amplified polymorphic DNA (RAPD) analysis of Escherichia coli isolated from chickens. FU Sag Bil Vet Derg 23: 1-4.

41. Chansiripornchai N, Ramasoota P, Sasipreeyajan J, Svenson SB (2001) Differentiation of avian pathogenic Escherichia coli (APEC) strains by random amplified polymorphic DNA (RAPD) analysis. Vet Microbiol 80: 75-83. 
Citation: Tamerat N, Muktar Y, Shiferaw D (2016) Application of Molecular Diagnostic Techniques for the Detection of E. coli O157:H7: A Review. J Vet Sci Technol 7: 362. doi:10.4172/2157-7579.1000362

42. Kanungo S (2009) A Simplified Analysis of Different Escherichia coli Strains by Using RAPD Technique. Not Bot Hort Agrobot Cluj 37: 257-260.

43. Viljoen GJ, Nelnad LH, Crowther JR (2005) Molecular Diagnostic PCR Hand Book. Springer Publishers, Pp: 32-40.

44. Stewart DS, Tortorello ML, Gendel SM (1998) Evaluation of DNA preparation techniques for detection of the SLT-1 gene of Escherichia coli O157: $\mathrm{H} 7$ in bovine faeces using the polymerase chain reaction. Lett Appl Microbiol 26: 93-97.

45. Shah DH, Shringi S, Besser TE, Call DR (2010) Molecular Detection of Food Borne Pathogens. CRC Press, Taylor \& Francis Group, USA, Pp: 309-369.

46. Nessa K, Ahmed D, Islam J, Kabir FML, Hossain MA (2007) Usefulness of a Multiplex PCR for Detection of Diarrheagenic Escherichia coli in a Diagnostic Microbiology Laboratory Setting. Bangladesh J Med Microbiol 1: 38-42.

47. Rashedul K (2011) Detection of Different Diarrheagenic Escherichia coli Strains by Multiplex PCR. Department of Microbiology, Mymensingh Medical College, Mymensingh, Bangladesh.

48. Toma C, Lu Y, Higa N, Nakasone N, Chinen I, et al. (2003) Multiplex PCR assay for identification of human diarrheagenic Escherichia coli. J Clin Microbiol 41: 2669-2671.

49. Newton CR, Graham A (1997) PCR. 2nd edn. Oxford: Bios Scientific, HongKong.

50. Livak KJ (2000) Quantitation of DNA/RNA Using Real-time PCR Detection

51. Patrinos GP, Ansorge WJ (2010) Molecular diagnosis. 2nd edn. Academic Press, 525 B Street, Suite 1900, San Diego, CA 92101-4495 USA, Pp: 89.

52. Spano G, Beneduce L, Terzi V, Stanca AM, Massa S (2005) Real-time PCR for the detection of Escherichia coli $\mathrm{O} 157: \mathrm{H} 7$ in dairy and cattle wastewater. Lett Appl Microbiol 40: 164-171.

53. Mclngvale SC, Elhanafi D, Drake MA (2002) Optimization of reverse transcriptase PCR to detect viable Shiga-toxin-producing Escherichia coli. Appl Environ Microbiol 68: 799-806.
54. Kushner SR (1996) mRNA decay. In: Escherichia coli and Salmonella cellular molecular biology. Neidhardt FC (Editor). American Society of Microbiology. Washington DC, USA, Pp: 849

55. Yaron S, Matthews KR (2002) A reverse transcriptase-polymerase chain reaction assay for detection of viable Escherichia coli O157:H7: investigation of specific target genes. J Appl Microbiol 92: 633-640.

56. Burnett SL, Beuchat LR (2002) Comparison of methods for fluorescent detection of viable, dead, and total Escherichia coli O157:H7 cells in suspensions and on apples using confocal scanning laser microscopy following treatment with sanitizers. Int J Food Microbiol 74: 37-45.

57. Yamaguchi N, Sasada M, Yamanaka M, Nasu M (2003) Rapid detection of respiring Escherichia coli 0157:H7 in apple juice, milk, and ground beef by flow cytometry. Cytometry A 54: 27-35.

58. Johnson PE, Lund ML, Shorthill RW, Swanson JE, Kellogg JL (2001) Rea time biodetection of individual pathogenic microorganisms in food and water. Biomed Sci Instrum 37: 191-196.

59. Call DR (2005) Challenges and opportunities for pathogen detection using DNA microarrays. Crit Rev Microbiol 31: 91-99.

60. Al-Khaldi SF, Martin SA, Rasooly A, Evans JD (2002) DNA microarray technology used for studying foodborne pathogens and microbial habitats: minireview. J AOAC Int 85: 906-910.

61. Kim H (2007) A molecular beacon DNA microarray system for rapid detection of $E$. coli $0157: \mathrm{H} 7$ that eliminates the risk of a false negative signal. Biosens Bioelectron 22: 1041-1047.

62. Liu Y, Gilchrist A, Zhang J, Li XF (2008) Detection of viable but nonculturable Escherichia coli O157:H7 bacteria in drinking water and river water. Appl Environ Microbiol 74: 1502-1507.

63. Lane S, Evermann J, Loge F, Call DR (2004) Amplicon secondary structure prevents target hybridization to oligonucleotide microarrays. Biosens Bioelectron 20: 728-735. 